\title{
Effect of Zinc Crystals Size on Galvanized Steel Deformation and Electrochemical Behavior
}

\author{
José Daniel Culcasi ${ }^{\mathrm{a}}$,Cecilia Inés Elsner ${ }^{\mathrm{b}}$, Alejandro Ramón Di Sarli ${ }^{\mathrm{b}}$ \\ ${ }^{a}$ Laboratorio de Investigaciones en Metalurgia Física - LIMF, \\ Facultad de Ingeniería-UNLP, \\ Av. 1 y 47. CP. B1900TAG La Plata, Argentina \\ ${ }^{\mathrm{b}}$ Centro de Investigación y Desarrollo en Tecnología de Pinturas - CIDEPINT, \\ (CIC-CCT-CONICET-La Plata) \\ Av. 52 s/n entre 121 y 122. CP. B1900AYB La Plata, Argentina
}

Received: September 18, 2008; Revised: April 30, 2009

\begin{abstract}
Hot-dip galvanized steel sheets with different spangle sizes were deformed by means of rolling and tension. The change of preferential crystallographic orientation and of superficial characteristics due to the deformation was analyzed by means of both X-rays diffraction and optical and scanning electronic microscopy. A correlation between such changes and the involving deformation modes was intended to be done and the spangle size influence on these modes was studied. Coating reactivity change due to the deformation was investigated by means of quasi-steady DC electrochemical tests. The results allow to infer that, in great spangle samples, the main deformation mechanism is twinning whereas in small spangle ones, pyramidal slip systems happen as well. The increase of the reactivity with the deformation is greater in tension than in rolling and it is more important in small than in great spangle samples.
\end{abstract}

Keywords: hot-dip galvanizing, deformation, texture, corrosion, X-ray diffraction

\section{Introduction}

Galvanized steel is a material that combines good formability and high corrosion resistance. Such properties make it capable to be used on a wide range of commercial applications. Galvanized steels usage on automotive industry has increased in the last years, what has promoted the analysis of its properties ${ }^{1-3}$. The most important properties within this context are formability, paintability, weldability, corrosion resistance, surface finishing and friction characteristics. The behavior of the material undergoing different deformation processes is a significant property, since it is influenced by the surface state and the friction characteristics, and conditions the paintability and corrosion resistance.

Regarding formability, an ideal coating is one that presents least friction and does not suffer cracks, powdering or flaking, or unacceptable cosmetic changes during deformation ${ }^{4-5}$.

Since zinc has a hcp crystal structure with few slipping systems, its deformation behavior when used as galvanic coating becomes highly dependent upon its crystallographic texture, crystals size, coating thickness and phase composition of the intermetallic layer ${ }^{6}$. Formability is also affected by intermetallic compounds and deformation temperature.

On bulk zinc, at room temperature, deformation occurs only by slip in close-packed $\langle 1120\rangle$ directions on (0002) basal plane. According to Schmid law, the crystals best positioned for slip are those in which basal plane is close to $45^{\circ}$ towards the load direction. Twinning is another important deformation mode of this material. This is a polar shearing mechanism, i.e. it may happen in only one direction. Twinning in zinc occurs when it is applied a tension in a direction parallel to the basal plane or a compression in a perpendicular direction to such a plane ${ }^{7}$. The deformation modes operating on zinc coatings are different, due to restrictions imposed by the Fe- $\mathrm{Zn}$ interface and to the limited thickness of the coating film. The literature reported that prismatic $(\{1 T 00\}<1120>)$ and pyrami- dal $(\{1122\}<11 \overline{23}>$ and $\{10 \mathrm{~T} 1\}<1210>)$ slip systems may become activated in zinc coatings, even at room temperature ${ }^{8-10}$.

If adequate slip or twinning conditions are limited, the coating will unavoidably suffer intergranular (grain boundary separation) or transgranular (cleavage) cracks.

Literature published about what happens during forming shows that authors have mainly been focused on understanding the effect of coating type, composition, thickness, etc. on the forming limits strain, strain distribution, lubrication characteristics, interface friction coefficient values, surface roughening, etc. ${ }^{11-16}$; also that information related with the formability effect on the corrosion behavior of galvanized coatings is limited. In this sense, from polarization resistance studies of uniaxally deformed galvanized steel, a slight increase of the zinc corrosion rate occurs as a function of the deformation degree ${ }^{17}$. It was also demonstrated that the loss in the hot-dip galvanized steel during its formability is high in biaxial mode, intermediate in plain strain mode, less in uniaxial and tensile modes of deformation, and that even in most deformed substrate the galvanic potential value is so negative as to prevent its corrosion ${ }^{18,19}$. All of these results imply that the corrosion behavior of coated sheets can be dependent on the deformation mode, i.e., different regions of the formed sheet may exhibit also different electrochemical reactivity.

In the present work, the texture evolution as a function of the tension and rolling deformation of hot-dip galvanized steel sheets with different grain sizes was analyzed, and possible deformation modes involved are presumed. Changes in the protecting performance of such samples were also studied.

\section{Materials and Methods}

Low carbon (drawing quality) $0.7 \mathrm{~mm}$ thick steel sheets were galvanized in a laboratory hot-dip galvanizing simulator ${ }^{20}$. The 
process took place by dipping the sheet for 30 seconds into a zinc alloy containing approximately $0.2 \%$ of $\mathrm{Al}$ and $0.12 \%$ of $\mathrm{Sb}$, at a temperature of $470 \pm 5{ }^{\circ} \mathrm{C}$. After the dipping time, the sheets were removed through a guide at a speed of $0.25 \mathrm{~m} / \mathrm{s}$, passing in front of an air knife. In order to get different spangle sizes (zinc dendritic crystals), one half of the samples underwent forced cooling with water spray whereas the other underwent natural cooling in contact with the environment.

The obtained samples were characterized by means of optical microscopy and X-ray diffraction, determining the spangle size and the coating thickness and crystallographic orientation.

The spangle size was determined by using the intersection method established in the ASTM E 112 standard. Grains were developed by applying the Palmerton reactive.

The coating thickness was gauged through optical microscopy (ASTM B 487 standard) and electromagnetic method (ASTM B-499/B-530 standard) using an Elcometer ${ }^{\circledR}$ equipment model 300.

The crystallographic orientation of the coating was determined using X-ray diffraction technique with $\mathrm{Cu}-\mathrm{K}_{\alpha}$ radiation, and a $2 \theta$ scan between $30^{\circ}$ and $100^{\circ}$. The coefficients of orientation were calculated according to the following method ${ }^{21}$ :

- The normalized intensity (In(hkil)) of each reflection was stated as the relationship between the relative intensities I(hkil) of the analyzed sample and those corresponding to a powder sample (Ip(hkil));

$I_{n_{(h k i l)}}=\frac{I_{(h k i l)}}{I_{p_{(h k i l)}}}$

- The intensities corresponding to a powders sample were obtained from the ASTM 4-831 chart;

- Finally, the orientation coefficient OC(hkil) was calculated as the ratio between the normalized intensity of the considered plane and the average normalized intensity; and

$$
O C_{(h k i l)}=\frac{I_{n_{(h k i)}}}{\frac{1}{m} \sum I_{n_{(h k i l)}}^{m}}
$$

where $m$ is the number of analyzed planes.

- According to this method, if a crystallographic plane has a $\mathrm{OC}($ hkil $)>1$, it indicates that there is a preferential orientation of grains with that plane parallel to the sheet surface in the analyzed sample.

Hot-dip galvanized steel sheets of $30 \times 150 \mathrm{~mm}$ were cut, classified in two groups according to the spangle size $(<1$ and $>2 \mathrm{~mm})$, and then deformed by means of rolling or tension until $10 \%$ strain. While rolling took place by passing only once a laboratory rolling mill STANAT TA 215 with rolls of $101.6 \mathrm{~mm}$ diameter, tension was carried out in a universal tests machine INSTRON ${ }^{\circledR}$ with a capacity of $50 \mathrm{kN}$, at a crosshead speed of $20 \mathrm{~mm} / \mathrm{min}$ and using a gage length of $40 \mathrm{~mm}$.

The deformed samples were characterized by using optic and scanning electronic microscopy and X-ray diffraction according to the method described above.

The corrosion behavior of either deformed or non-deformed samples was evaluated by means of quasi-steady DC potentiostatic electrochemical tests swept at different potential ranges. In order to gain that goal, an electrochemical cell "ad-hoc" was used. In it, the galvanized steel sheet was the working electrode, a graphite cylinder the auxiliary electrode and a saturated calomel electrode (SCE) the reference one. The electrolyte was $0.05 \mathrm{M} \mathrm{NaCl}$ solution with a dissolved oxygen concentration of $21.82 \mathrm{mg} . \mathrm{L}^{-1}$. All the tests were carried out at room temperature $\left(22 \pm 2{ }^{\circ} \mathrm{C}\right)$ and without electrolyte stirring. In order to obtain only the coating electrochemical response, the samples edges were masked with wax, leaving $\sim 3 \mathrm{~cm}^{2}$ of exposed area. The potential swept were accomplished with a potentiostatgalvanostat EG\&G PAR 273A driven by the Softcorr ${ }^{\circledR}$ software.

The quasi-steady polarization curves were plotted in the potential (E) range open circuit or corrosion potential $\left(\mathrm{E}_{\mathrm{ca}}\right) \pm 20 \mathrm{mV}$. Polarization resistance $\left(R_{p}\right)$ values were determined from the slop of the current density $(j)$ vs. E curves near the $E_{c a}$. Polarization curves were also obtained in the interval $\mathrm{E}_{\mathrm{ca}} \pm 250 \mathrm{mV}$ and, in this condition, the coating corrosion potential and corrosion current values were defined in terms of the deformation mode. The values of these parameters summarized in the respective figures are the average of eight samples tested in each condition.

\section{Results and Discussion}

Independently of the cooling condition, the coatings average thickness was $40 \mu \mathrm{m}$. Besides, it is important to denote that the presence of $\mathrm{Fe}-\mathrm{Zn}$ intermetallic compounds was not observed in any sample.

On the other hand, all the non-deformed samples showed a strong (0002) basal orientation, Figure 1.

On the contrary, an important change of crystallographic orientation took place as consequence of the applied deformation, Figures 2 and 3. In such a sense, while that mainly developed towards prismatic orientation $\{10 \mathrm{~T} 0\}$ and, in a lesser way, great angle pyramidal $\{10 \mathrm{~T} 1\}$ and $\{2021\}$ orientations, the basal orientation decreased. The evolution towards the prismatic orientation was more important in the great spangle samples, whereas the small ones developed towards a more homogeneous orientation. Although the tendency was the same, the orientation change caused by tension is smaller than that caused by rolling. This behavior could be supported in the fact that during tension application there is lesser deformation of the zinc crystals and greater fissuring by grain boundaries opening.

The main load working during rolling is a compression perpendicular to the sheet plane. This compressive stress induces a rotation of crystals so that the slip plane is located perpendicular to the load application axis, i.e. parallel to the sheet plane. The load working during the tension, tangential to the sheet plane, tends to make a similar crystal rotation, i.e. the slip planes tend to be located parallel to the one of the sheet.

The main slip system of zinc is the $(0001)<1120>$; its activation would have the crystals rotated so that the basal plane is located parallel to the sheet plane and increments the basal texture. The evolution observed in the texture is evidence that the working deformation modes are others.

The prismatic (10T0) orientation increase may be explained by the twinning. The twinning plane in zinc is the (10T2) and the shearing direction is the [T011]; this twinning system generates a crystal rotation of approximately $94^{\circ}$ around the direction [1120]. This implies that the planes (10T0), which initially were in a position more or less perpendicular to the sheet plane, will be approximately parallel to it after the shearing.

As twinning does not justify the increase of other orientations it is necessary that other deformation modes must have necessarily been activated. Some works dealing with galvanic coatings have reported the activation of less active systems in bulk zinc ${ }^{8,10}$.

In studies carried out on galvanized sheets subjected to tension, by combined use of optical microscopy and electron backscattered diffraction pyramidal $(\{2 \Pi 2\}<2 \Pi 3>$ and $\{10 \Pi 1\}<1120>)$, and 


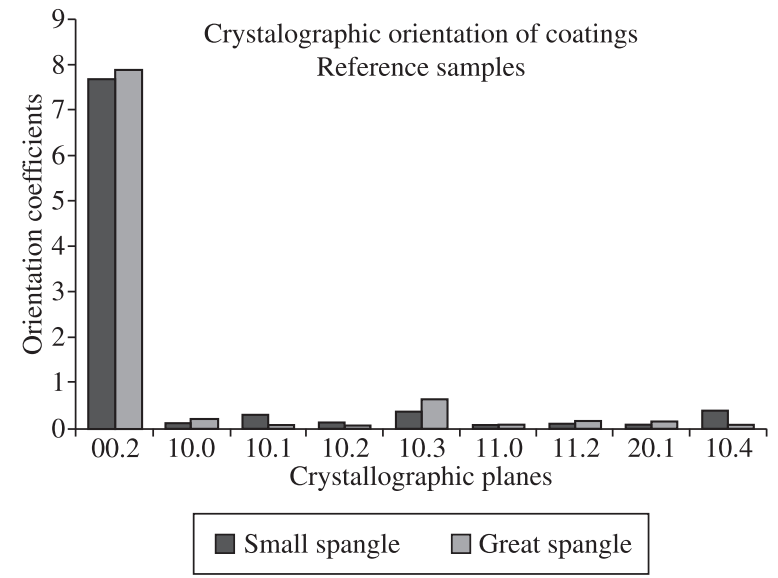

Figure 1. Orientation coefficients of galvanized samples.

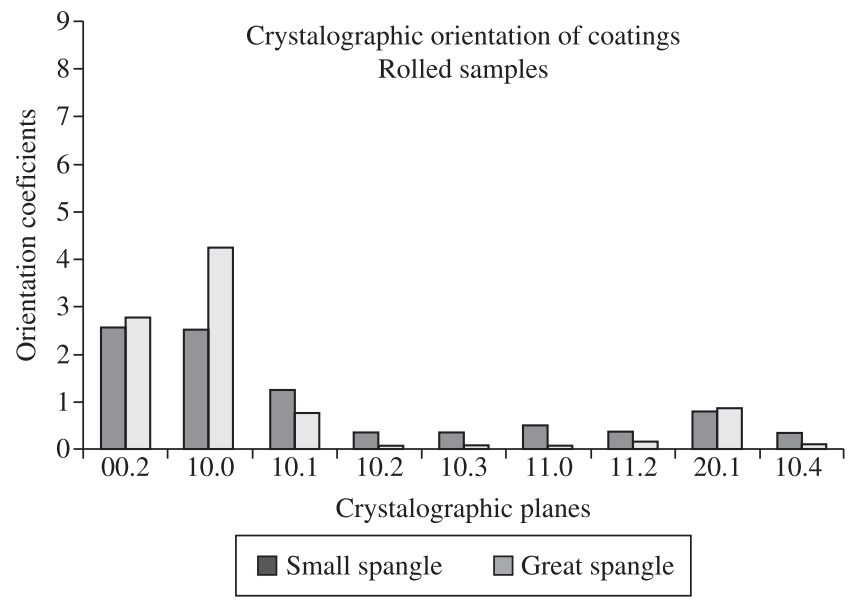

Figure 2. Orientation coefficients of the rolled galvanized samples.

prismatic $\{10 \mathrm{~T} 0\}<1120>$ slip systems were identified ${ }^{8}$. The activity of these deformation systems was greater than in the basal systems.

By modeling the tension process according to the self-consistent viscoplastic model, it could be established that the texture resulting after a $10 \%$ strain corresponds to an activity of approximately $60 \%$ of the pyramidal system $\{2 \Pi 2\}<2 \Pi 3>, 35 \%$ of the basal system and $5 \%$ of twinning ${ }^{10}$.

Figures 2 and 3 show that the twinning prevailed in great spangle samples (prismatic orientation increase), whereas the pyramidal slip system did it in the small spangle ones. The twinning predominance in the first case could be due to the fact that twins would have more freedom to expand laterally.

The metallographic analysis without etching clearly shows twins, mainly in the stretched samples, and grain boundaries separation, Figures 4 and 5.

Figures 6 and 7 illustrate some $\log j$ vs. E curves obtained in the potential range $\mathrm{E}_{\mathrm{ca}} \pm 250 \mathrm{mV}$ for samples either non-deformed (reference) or deformed by rolling or tension. It must be highlighted that in spite of the unfeasibility to reproduce exactly the reference samples surface and the great number of variables involved in the different processes that the tested samples underwent, the indicative tendencies of the effect of each deformation mode were clear and qualitatively reproducible.

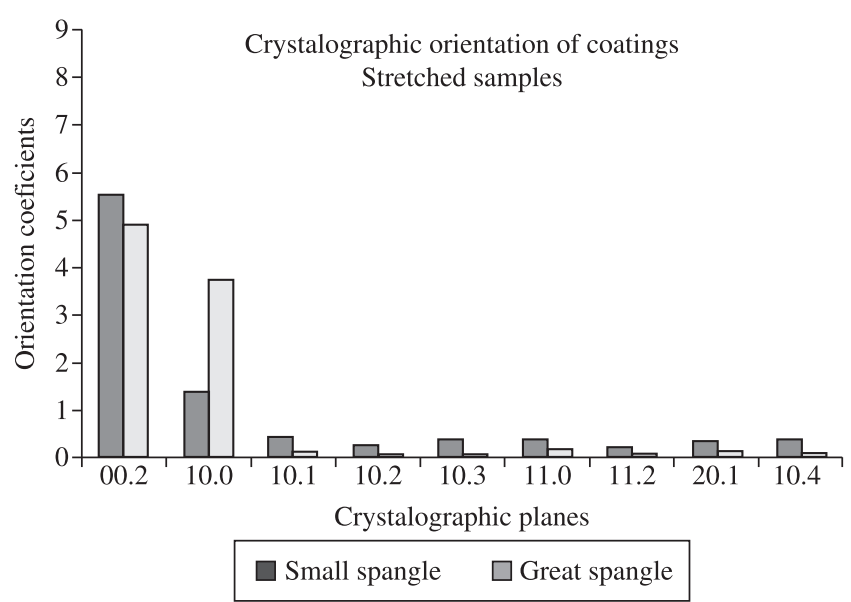

Figure 3. Orientation coefficients of the stretched galvanized samples.

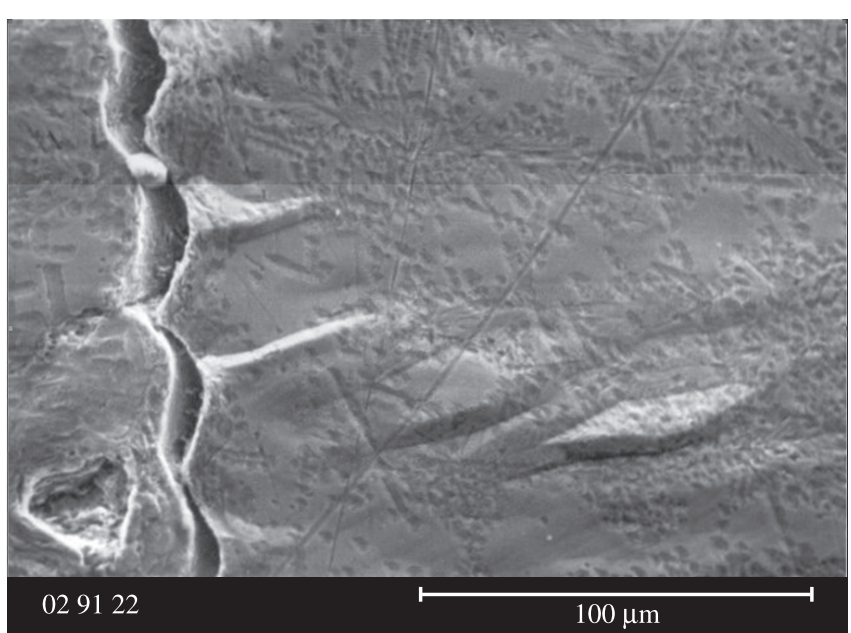

(a)

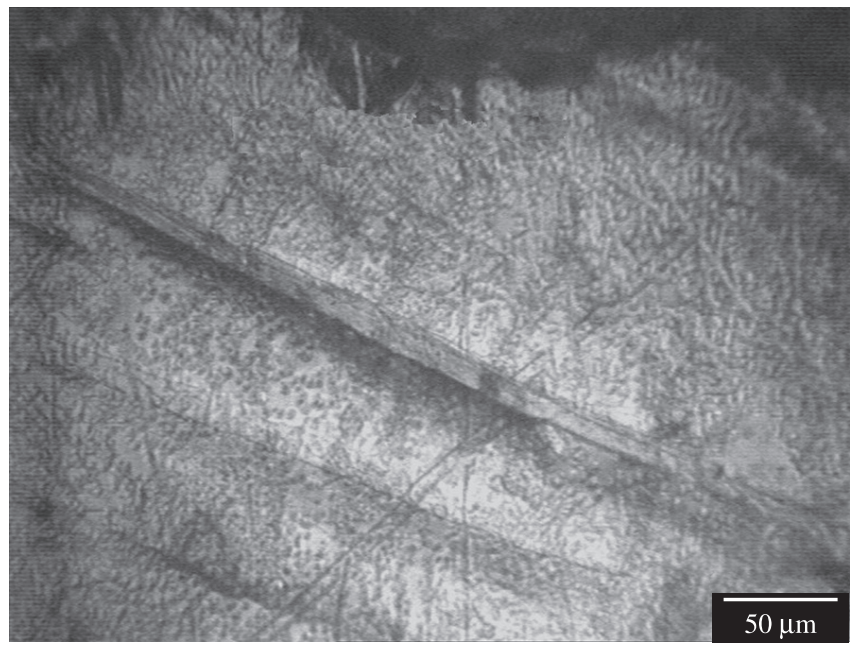

(b)

Figure 4. Micrographs of stretched great spangle samples. a) SEM; b) Optical microscopy.

A simple analysis of the figures allows inferring that the inducing corrosion effect caused by tension was more important in small than in great spangle samples. In addition, independently of the spangle size taken into account, it can be seen a tendency to increase the 


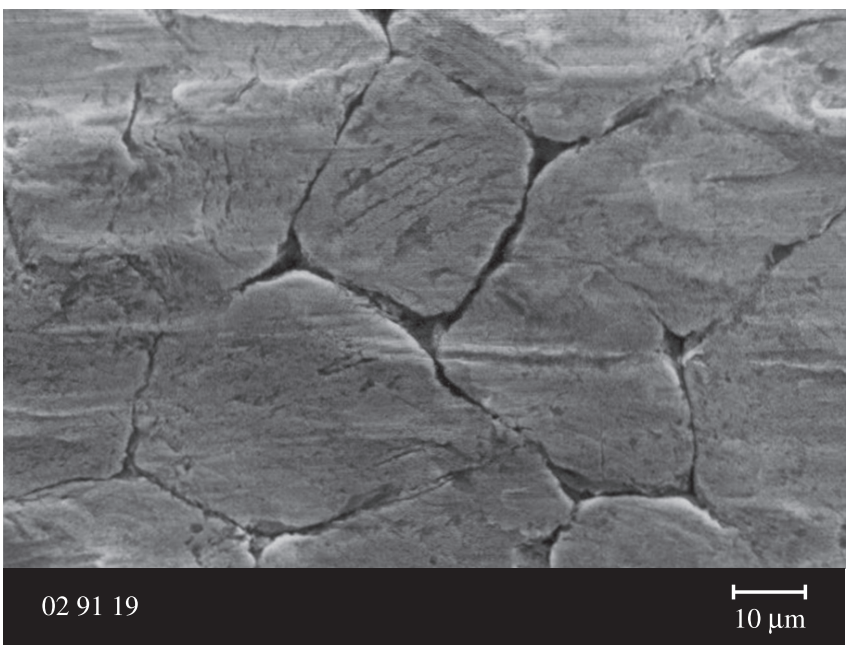

(a)

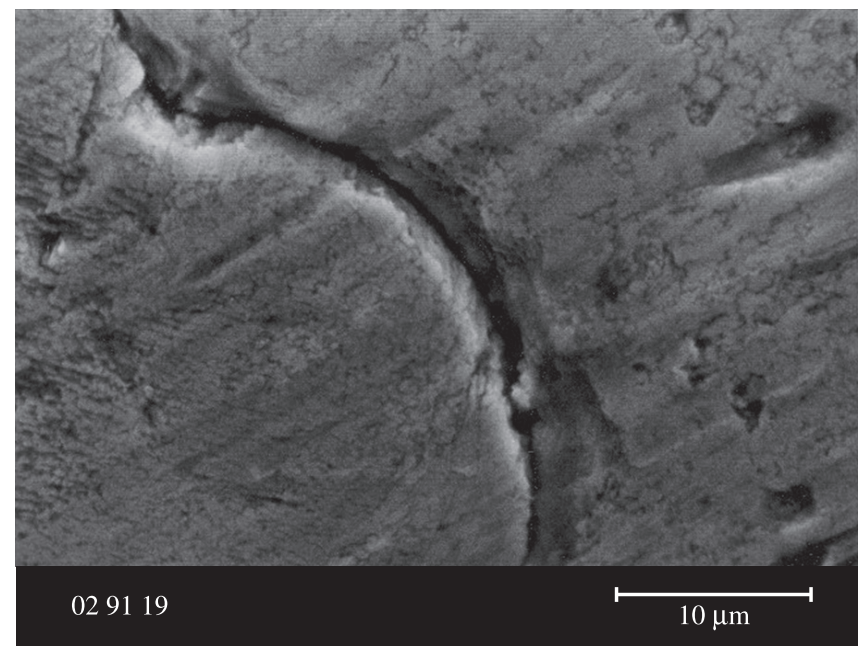

(b)

Figure 5. Micrographs of rolled samples (SEM). a) Small spangle and b) Great spangle.

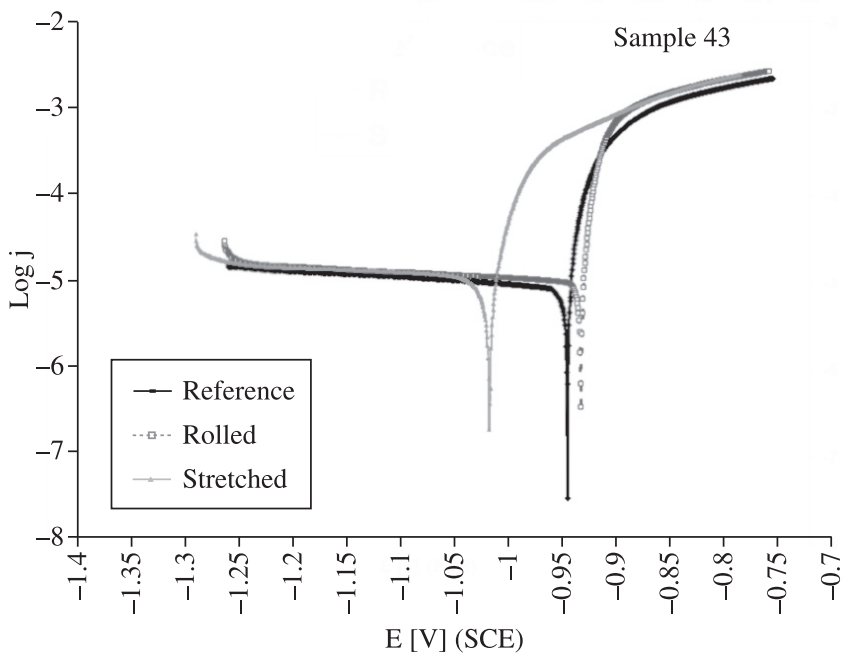

(a)

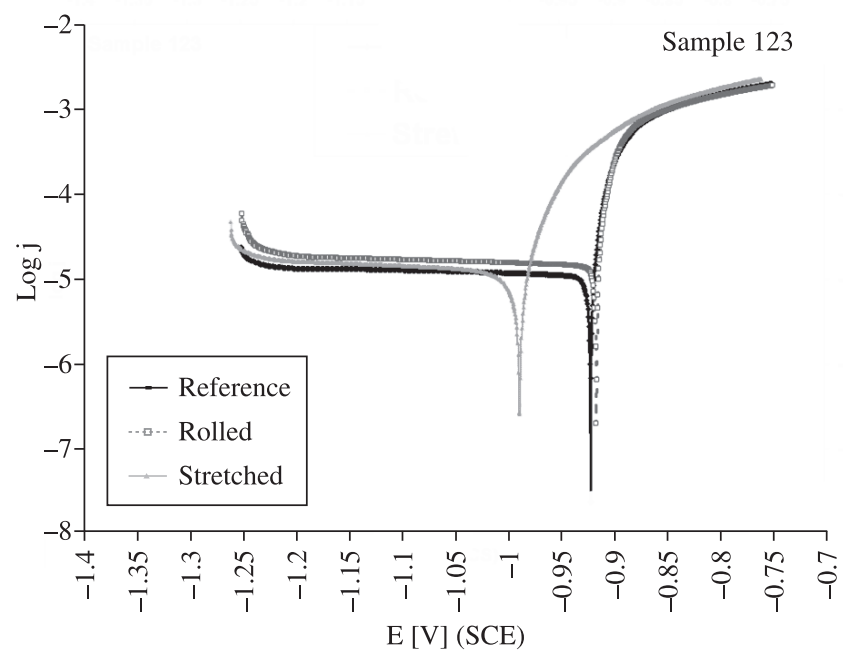

(b)

Figure 6. Polarization curves corresponding to two small spangle samples.

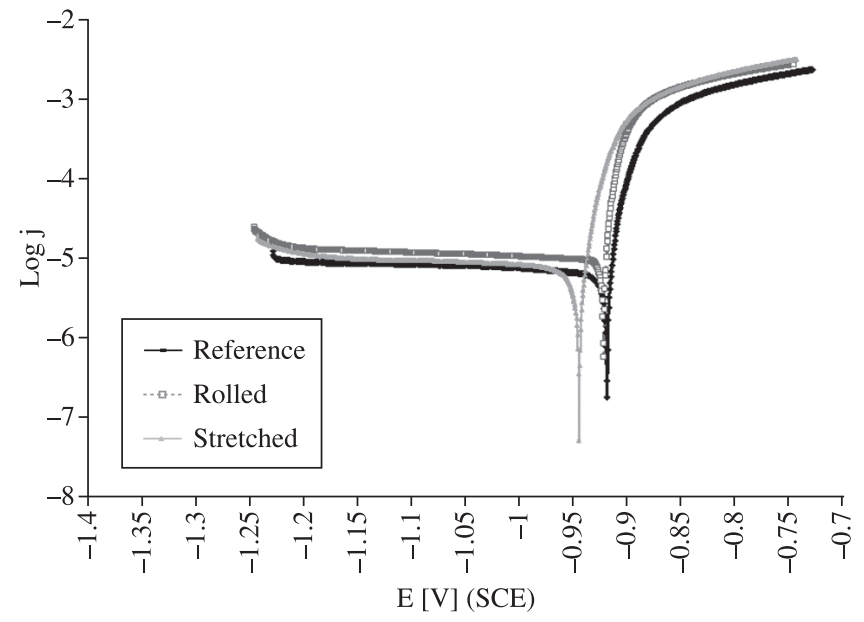

(a)

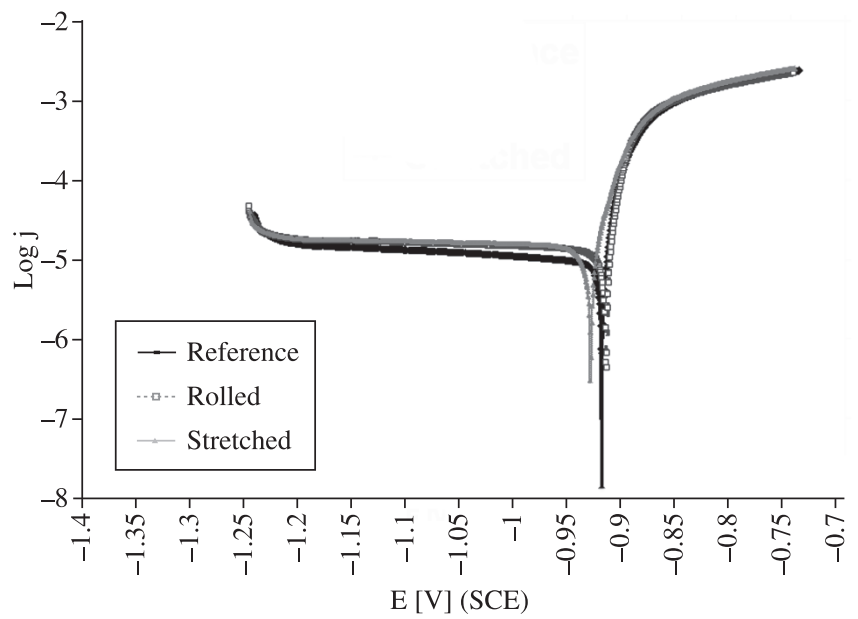

(b)

Figure 7. Polarization curves corresponding to two great spangle samples. 
coating electrochemical activity (corrosion potential displacement towards more negative values) after applying deformation by tension, whereas the effects of the rolling not only was less significant $(\leq 20 \mathrm{mV})$ but also provoked, in general, a displacement towards more positive values. This greater reactivity of the samples subjected to tension would be due to greater fissuring by grain boundaries opening generated by the tension.

The polarization curves reveal that the anodic process kinetics is controlled by activation and the cathodic one by diffusion (material transport). This implies that the value of the coating corrosion rate cannot be determined by using the Tafel's extrapolation method. Nevertheless, as only a comparative evaluation of the coating behavior in terms of the deforming mode was sought, the $\mathrm{j}_{\text {corr }}$ value was determined from an alternative method based on extrapolating the anodic curve slope up to the corrosion potential in the potential range for which the sample surface was free of corrosion products ${ }^{22}$.

Figures 6 and 7 exhibit the typical behavior of zinc in $\mathrm{NaCl}$ solution: the significant increase in anodic current density with the potential indicates that the coating undergoes active dissolution during anodic polarization, which is confirmed by the fact that all the anodic curves show Tafel slopes of a few $\mathrm{mV} /$ decade. The dissolution process is assisted by the $\mathrm{Cl}^{-}$ions forming part of the electrolyte, and whose main role is acting as a catalyst for the development of complex compounds $\mathrm{Cl}-\mathrm{Zn}-\mathrm{OH}$ as, for example, $\mathrm{Zn}_{6}(\mathrm{OH})_{8} \mathrm{Cl}_{2}$, (simonkolleite) ${ }^{23}$. Such compounds further facilitate the access of the electrolyte to zinc accelerating the corrosion process ${ }^{24}$.

On the other hand, the barrier formed by corrosion products has the possibility of reducing the anodic current flow during the early steps of polarization. Muster et al. ${ }^{25}$ reported that, if as occurred in the discussed results, the electrolyte is maintained at ambient conditions, the dissolved $\mathrm{CO}_{2}$ converts some of the zinc hydroxides to a complex hydrated zinc carbonate $\left(\mathrm{Zn}_{5}\left(\mathrm{CO}_{3}\right)_{2}(\mathrm{OH})_{6}\right.$, hydrozincite $)^{23}$, which support the mentioned effect. Nevertheless, in increasing the anodic potentials, the oxides turn out unable to resist the current flow and the polarized sample shows an increasing anodic current density.

Figure 8 illustrates the corrosion current density $\left(\mathrm{j}_{\text {corr }}\right)$ dependence with the deformation mode. Because of the little samples surface homogeneity, it was more convenient to chart the corresponding dispersion of the average values of $j_{\text {corr }}$ obtained from the eight samples tested in each condition.

A deeper analyses of the obtained experimental data allow seeing that, independently of the spangle size, the $j_{\text {corr }}$ values were greater for deformed than for reference samples. In accordance with the Scully's interpretation ${ }^{26}$, the results can be explained assuming that when the relative intensity of (0002) basal plane texture (RIBPT) is high, as occurs in the reference samples, it can be concluded the surface is mainly covered with basal planes parallels to the sheet surface. These planes have the highest binding energy of the surface atoms; therefore, the total energy involved in both the bonds breaking and the subsequent atoms dissolution is also the highest. Consequently, such a surface becomes electrochemically less active due to the surface energy, whose value is inversely proportional to the atomic spacing, is lowest for basal planes than for others planes in hep structure ${ }^{27}$. It makes that coatings having higher RIBPT components is corroded slower than those with lower RIBPT, Figure 8. However, when this type of components decreases it means that the RIBPT are replaced with other planes such as prismatic and/or high angle pyramidal planes, Figures 1-3. Because of their higher surface energy or lower interatomic binding energy, the corrosion resistance of these planes is low and therefore the coating becomes weaker against corrosion $^{26}$. In this sense, the corrosion rate increment, which was greater for the tension than for the rolling samples, was ascribed to the greater intergranular cracking caused by the first, which lead to the cathodic reaction depolarization due to the sum of two effects. The first, an increment of the zinc area available for the oxygen reduction reaction since it could occur on the surface of the intact zinc layer and within it, on the wall of its defects provoked by the sample deformation. Added to this, another component of the cathodic current must be taken into consideration due to the exposure of some underlying bare steel at the bottom of these coating defects. Since the exchange current density for hydrogen evolution $\left(\mathrm{j}_{\mathrm{OH}+\mathrm{H}}\right)$ on steel is much higher than on $\mathrm{zinc}^{28}$, once the steel is exposed it facilitates a higher rate of hydrogen evolution and, hence, to the increases of the cathodic current.

Results of linear polarization tests in the potential range $\mathrm{E}_{\mathrm{ca}} \pm 20 \mathrm{mV}$ confirm that the polarization resistance $\left(\mathrm{R}_{\mathrm{p}}\right)$ value, which is inversely proportional to the corrosion rate one, decreased once some deformation mode was applied, and that such effect became more important for stretched than for rolling samples, Figure 9.

Notwithstanding $j_{\text {corr }}$ and $R_{p}$ changes were small (in the same order of magnitude), they state a clear tendency. Contrary to what happened with the corrosion potential values, differences in the corrosion rate of great or small spangle samples were not appreciated.

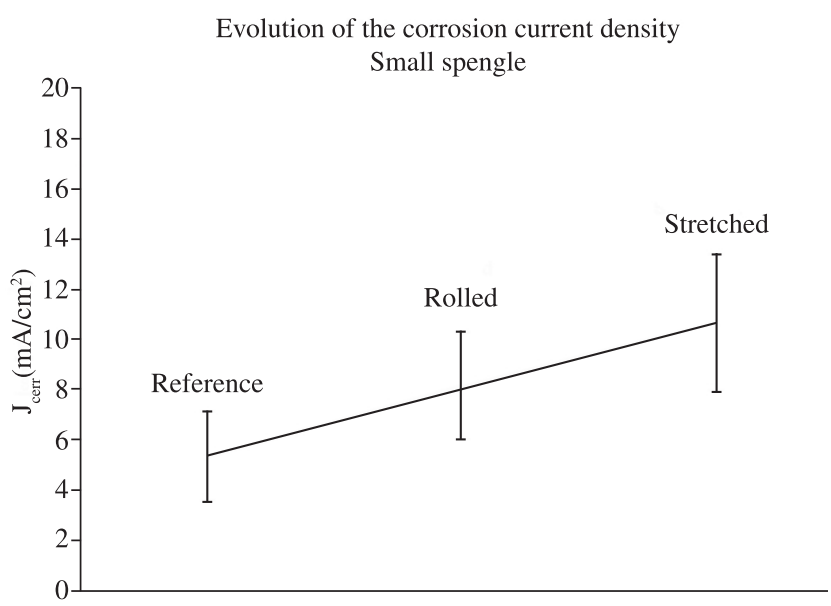

(a)

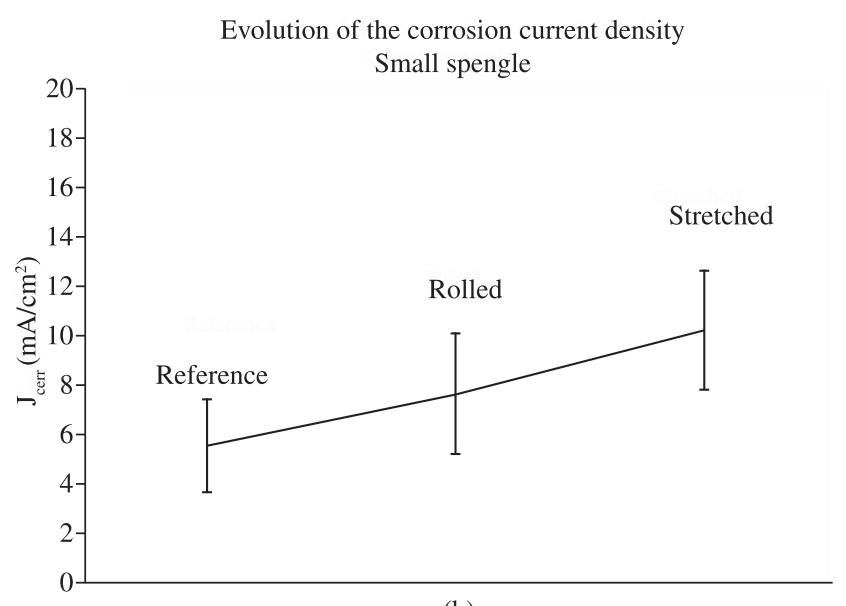

(b)

Figure 8. Corrosion current density dependence on the deformation type. a) Small spangle and b) Great spangle. 


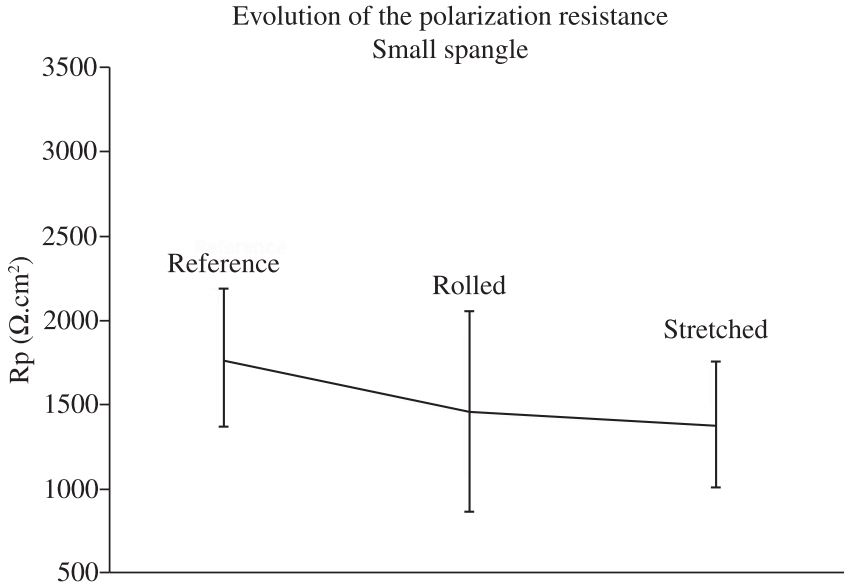

(a)

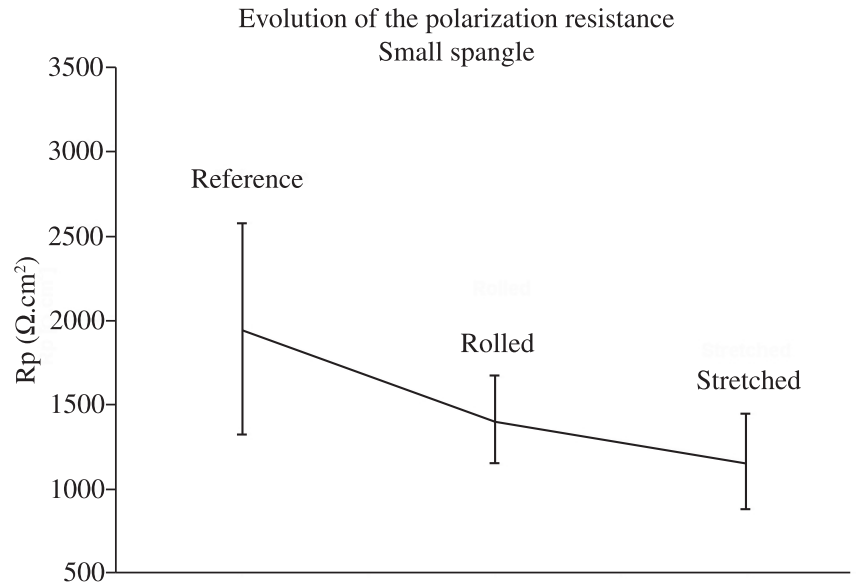

(b)

Figure 9. Polarization resistance dependence on the deformation type. a) Small spangle; b) Great spangle.

\section{Conclusions}

The corrosion behavior of galvanized steel sheets, as assessed from linear polarization measurements, was studied before and after appropriate mechanical deformation of the samples. The material was characterized from a microstructural point of view by microscopy and microanalysis techniques. From these studies, the following conclusions were derived:

- Hot-dip galvanized process generates a strong basal texture which turns towards prismatic and pyramidal textures because of deformation;

- At equal strain, the crystallographic orientation changes are more important for rolling than for tension deformation mode;

- Tension produces greater intergranular cracking and lesser deformation of the zinc crystals;

- The deformation modes working in the zinc coating are mainly twinning and slipping according to the pyramidal and prismatic systems;

- Twinning is more important in the great spangle, whereas intergranular cracking is more important in the small spangle coatings;

- Even though small, changes of corrosion current density and polarization resistance values denote a clear increasing tendency of the coating electrochemical reactivity with the deformation. Such effect is more noteworthy with the tension deformation; and

- The corrosion potential displacement provoked by the tension deformation mode is more significant in small than in great spangle samples.

\section{References}

1. Tzimas E and Papadimitriou G. Cracking mechanisms in high temperature hot-dip galvanized coatings. Surface and Coatings Technology, 2001; 145(1-3):176-185.

2. Vincent G, Bonasso N, Lecomte JS, Colinet B, Gay B and Esling C. The relationship between the fracture toughness and grain boundary characteristics in hot-dip galvanized zinc coatings. Journal of Materials Science, 2006; 41(18):5966-5975.
3. Elvins J, Spittle JÁ and Worsley DA. Relationship between microstructure and corrosion resistance in $\mathrm{Zn}-\mathrm{Al}$ alloy coated galvanized steels. Corrosion Engineering, Science and Technology, 2003; 38(3):197-204.

4. Gronostajaski JZ, Ali WJ and Ghattas MS. The effect of deformation on the corrosion resistance of coated steel sheets. Journal of Materials Processing Technology, 1990; 23(1):21-28.

5. Shah SR, Dilewinjs JÁ and Jones RD. The structure and deformation of zinc-rich coatings on steel sheet. Journal of Materials Engineering and Performance, 1996; 5(5):601-608.

6. Gupta AK and Ravi Kumar D. Formability of galvanized interstitialfree steel sheets. Journal of Materials Processing Technology, 2006; 172(2):225-237.

7. Reed Hill RE. Principios de metalurgia física. 3 ed. México: C.E.C.S.A.; 1972. p. 500.

8. Parisot R, Farest S, Pineau A, Grillon F, Demonet X and Mataigne JM. Deformation and damage mechanisms of zinc coating on hot-dip steel sheets: Part I. Deformation modes. Metallurgical and Materials Transactions A. 2004; 35(3):797-811.

9. Sánchez P, Ortiz M, Pochettino A and Iurman L. Texturas de depósitos de cinc sobre chapas de acero. In: $15^{\text {th }}$ IAS Conference; 2004; San Nicolás, p. 404-413.

10. Sánchez P, Pochettino A and Iurman L. Modelización de texturas de deformación en recubrimientos de Zn. In: Congreso Binacional SAM/ CONAMET-Jornadas MEMAT 2005; 2005; Mar del Plata, p. 47-52.

11. Lovell MR and Deng Z. Characterization of interfacial friction in coated sheet steels: influence of stamping process parameters and wear mechanisms. Tribology International, 2002; 35(2):85-95.

12. Jiang HM, Chen XP, Wu $\mathrm{H}$ and $\mathrm{Li} \mathrm{CH}$. Forming characteristics and mechanical parameter sensitivity study on pre-phosphated electrogalvanized sheet steel. Journal of Materials Processing Technology, 2004; 151(1-3):248-254.

13. Lin KL, Chue $\mathrm{CH}$ and Kou BC. Deformation and corrosion of hot dip galvanized coatings. Materials Chemistry and Physics, 1997; 50(1):82-87.

14. Abotani K, Hirohata K and Kiyasu T. Hot-Dip galvanized sheet steel with excellent press formability and surface quality for the automotive panels. Kawasaki Steel Giho. 2002; 34(2):66-70.

15. Wichern CM, De Cooman BC and Van Tyne CJ. Surface roughness changes on a hot-dipped galvanized sheet steel during deformation at low strain levels. Acta Materialia. 2004; 52(5):1211-1222. 
16. Toroghineja MR and Ashrafizadeh F. Effect of coating thickness on formability of hot-dip galvanized low carbon steel sheet. The Iron and Steel Institute of Japan International, 2007; 47(10):1510-1517.

17. Sacco EA, Alvarez NB, Culcasi JD, Elsner CI and Di Sarli AR. Effect of the plastic deformation on the electrochemical behavior of metal coated steel sheets. Surface and Coatings Technology, 2003; 168(2-3):115-122.

18. Vagge ST, Raja VS and Ganesh Narayanan R. Effect of deformation on the electrochemical behavior of hot-dip galvanized steel sheets. Applied Surface Science, 2007; 253(20):8415-8421.

19. Raja VS, Panday CK, Saji VS, Vagge ST and Narasimhan K. An electrochemical study on deformed galvanneal steel sheets. Surface and Coatings Technology 2006; 201(6):2296-2302.

20. Seré PR, Mugica GW and Culcasi JD. Desarrollo de un simulador del proceso de galvanizado por inmersión. In: Jornadas SAM ' 97 y $1^{\text {er }}$ Taller Nacional sobre Materiales para la Construcción; Universidad Nacional del Centro-Tandil, Prov. de Buenos Aires, Argentina; 1997. p. 327-330.

21. Shaffer SJ, Morris Jr. JW and Wenk HR. In: Symposium On Zinc-Based Coating Systems: Metallurgy and Performance; 1990; G Krauss and DK. Matloch (Eds.). TMS Warrendale, PA: The Minerals, Metals \& Materials Society; 1990: p.129-140.
22. Dattilo M. Polarization and corrosion of electrogalvanized steelevaluation of zinc coatings obtained from waste-derived zinc electrolytes. Journal of Electrochemical Society, 1985; 132(11):2557-2561.

23. Odnevall I. Atmospheric corrosion of field exposed zinc-A multianalytical characterisation of corrosion products from initial films to fully developed layers. [Doctoral Thesis]. Stockholm: Department of Materials Science and Engineering, Royal Institute of Technology; 1994.

24. Arenas MA and Damborenea JD. Use of EIS to study corrosion of galvanised steel in $0.6 \mathrm{M} \mathrm{NaCl}$ solution. Corrosion Engineering, Science and Technology, 2006; 41(3):228-234.

25. Muster TH and Cole IS. The protective nature of passivation films on zinc: surface charge. Corrosion Science, 2004; 46(9):2319-2335.

26. Scully JC. The fundamentals of corrosion. 2 edition. Oxford: Pergamon Press; 1990.

27. Seré PR, Culcasi JD, Elsner CI and Di Sarli AR. Relationship between texture and corrosion resistance in hot-dip galvanized steel sheets. Surface and Coatings Technology, 1999; 122(2-3):143-149.

28. Bockris JEO and Reddy AKN. Modern Electrochemistry. New York: Plenum Press; 1970. 